\title{
PERSONAL PROFILE AND SOCIAL ORIENTATIONS IN THE INTERPERSONAL RELATIONSHIPS AMONG STUDENTS IN THE FIELD OF HEALTH CARE
}

\author{
M. Bacheva* \\ Department of Health Care, Faculty of Public Health, Health Care and Sports, \\ South-Western University "Neofit Rilski", Blagoevgrad, Bulgaria
}

\begin{abstract}
The PURPOSE of this study is to investigate the level of assertive behavior and selfesteem in students, teaching nurses and midwives, and to shape their personal profile and social orientations in interpersonal relationships.

MATERIAL and METHODS: Were investigated 44 students studying in the nursing and midwifery profession for the level of the assertiveness and the behavior in interpersonal relationships. The research was carried out by a test method, with the following questionnaires specifically applied: Personality scale for the study of assertiveness- J. Tindall, Scale for the study of global self-esteem"- M. Rozenberg, Test for interpersonal relationships- T. Leary, were also studied.

RESULTS: The results do not differ statistically significant from the normative sample, i.e. students studying to be nurses and midwives randomized to participate in this study demonstrated a level of assertiveness and self-esteem within the norm. However, there is a slight tendency for higher results in the group of midwives in terms of assertiveness and self-esteem.

CONCLUSION: Students studying in both regulated professions should be encouraged to generate assertive skills. By establishing the characteristics of personality traits, which builds the profile of the medical specialist, can be considered as target units and stimulates appropriate socially significant orientation in behavior, corresponding to the needs of the two regulated professions.
\end{abstract}

Key words: assertiveness, self-esteem, interpersonal relationships, students, health care

\section{INTRODUCTION}

Today, nurses and midwives are moving away from the traditional subordinate role, increasingly recognizing that they need to behave in an affirmative manner. Global nursing defines assertive behavior as an invaluable element of successful professional practice. Assertive nurses are able to make suggestions in a direct and convenient way, know how to give and receive criticism, respect the rights of others and act responsibly in nursing situations,

\footnotetext{
Correspondence to: Mariana Bacheva Southwestern University "Neofit Rilski" Blagoevgrad, Faculty of Public Health, Health Care and Sports, Department of Health Care, Bulgaria, Blagoevgrad 2700, Bratya Miladinovi Str; 21,e-mail: bachewa@abv.bg
}

assessing problems through a thought process focused on solving them (9).

There are differences in the interpretation of the concept of assertiveness. Some authors understand the concept as self-sufficiency and self-confidence (1), others associate it with understanding, respect and acceptance of others (2-4). Summarizing the various concepts Peneva, I. defines assertiveness as a "complex multicomponent personality construct" and derives the basic elements such as "the presence of self-confidence, self-esteem and respect for others, the ability to actively defend their interests and openly state their goals, intentions and feelings, without harming the interests of others" (5). 
Assertiveness is perceived as healthy behavior and is one of the main components of effective communication of health care professionals in interaction with patients, colleagues and other health professionals. . There is evidence in the literature that nurses lack assertive skills and are accepted in passivity, and obedience to other medical professionals, with almost no data on assertiveness in midwives. According to these data, they rarely disagree with the opinions of other medical professionals and are unable to provide constructive criticism. This lack of self-confidence leads to reduced communication efficiency and compromised patient care (6). Assertiveness means speaking up for one's interpersonal freedoms or as required by one's role responsibilities to engage others in finding viable, stable solutions. Assertiveness is a learnable skill rather than a personality characteristic (7).

Other studies on assertive behavior focus on potential barriers and factors that prevent this behavior. To them they refer some traditional training, fear, the working atmosphere, and some hierarchical structures within the hospitals, which express mixed feelings about the usefulness of assertive trainings. Factors that promote confidence include knowledge, experience, wearing a uniform (8).

The present study is guided by Timothy Leary's theory of interpersonal relationships, according to which in relationships with other people a person most often shows two tendencies: to dominate or obey, to show friendliness or hostility to them. The study is based on the idea that the two factors of dominance obedience, friendliness - hostility determine the general impression of man in the process of interpersonal perception (10).

In a previous study of stress during training of students of medical specialties were identified our factors that directly or indirectly hinder their learning and development and offer a model for promoting adaptation $(11,12)$.

The study was also provoked by Hildegard Peplau's theory of interpersonal relationships in nurses, according to which any interaction with patients becomes an important therapeutic opportunity for nurses towards them (13).

The focus of the theory is primarily on the therapeutic process between nurses and their patients, rather than on pathology. The ability of nurses to carefully guide the individual phases described by Peplau, the ability to have therapeutic conversations and maintain professional relationships with their patients, largely depends on self-affirming behavior and personality traits that are part of the personality of the health care professional. These two theories also emphasize the importance of the caregiver's ability to understand his or her own behavior in order to help others (13).

In order to provide professional and competent care for patients, a relationship of trust with the patient must be developed. Extremely important for patients is nursing care, which concerns somatic disease, but also of particular importance for the healing process is the emotional appearance of medical staff (14). Based on this theory, one can derive the expectations for the skills that the nurse / midwife must possess, namely to be confident in her work in order to provide competent care for her patients. To optimize his personal psychological resources for reflection, recognition, empathy, social skills and effective communication (14).

The issue which the present study focuses on is related to the study of the level of assertiveness and self-esteem, as well as the peculiarities of the behavior in interpersonal relationships in students studying in the nursing and midwifery profession.

The study aims to trace the trends in the state of assertiveness and self-esteem and their mental qualities in students studying in the field of "Health Care". The secondary goal of the study is to establish the features of the traits that are part of the personality of the health care professional and social orientations, giving information about his behavior in interpersonal relationships. 


\section{METHODS}

Several databases of publications related to assertiveness in nurses and midwives have been studied, as well as relevant factors expressing confidence in the clinical environment, as well as articles assessing assertiveness and interpersonal behavior in nursing students and midwives. The research was carried out by a test method, with the following questionnaires specifically applied:

- $\quad$ "Personality scale for the study of assertiveness", ed. by J. Tindall, Bulgarian adaptation - I. Peneva (Peneva I., 2012).

- $\quad$ "Scale for the study of global selfesteem", creator - M. Rozenberg and Bulgarian adaptation - I. Peneva and S. Stoyanova (Peneva I., Stoyanova S., 2011).

- "Test for interpersonal relationships"- $\quad$ (Sobchik, LN Diagnosis of interpersonal relationships. A modified version of interpersonal diagnosis T. Leary. Methodological guide. M., 1990)

The questionnaires were attached to a sample of students studying at the Department of Health Care at SWU "Neofit Rilski". The sample included 44 first- and second-year students majoring in Nursing and Midwifery. After the selection of the respondents, informed consents were obtained and data were collected on the average values in the two groups of specialties and search for differences in the level of assertiveness, the level of global self-esteem and their behavior in interpersonal relationships, as well as some correlations between variables. (16)

The data processing was performed through the statistical system SPSS-19.0. The hypotheses were tested by applying the statistical procedures $\mathrm{T}$-test for one sample, T-test for two independent samples, one-factor stepwise regression analysis. Pearson- correlation coefficients were used to determine the relationship between confidence, specialty, and internship level. A correlation was also sought between the different sectors (octants), which include the peculiarities of the traits in the behavior (16). The obtained statistical data are presented in tables and are displayed in the text, using the following notations:

$M$ - value of the arithmetic mean;

$S D$ - value of the standard deviation;

$t$ - empirical value of $t$ - Student's criterion;

$d f$ - degrees of freedom of data distribution;

$p$ - significance level of $t$ - Student's criterion.

\section{RESULTS}

Table 1 presents the results of the test for testing assertiveness in nursing students and the percentage distribution by individual factors (Table 1).

Table 1. Personality scale for the study of assertiveness in students (in \% of subjects) and its constituent factors.

\begin{tabular}{|l|l|l|l|l|}
\hline $\begin{array}{l}\text { Level } \\
\text { expression }\end{array}$ & $\begin{array}{l}\text { Factor I - } \\
\text { "Protection of } \\
\text { personal and } \\
\text { consumer } \\
\text { rights" }\end{array}$ & $\begin{array}{l}\text { Factor II - Confidence } \\
\text { and initiative" }\end{array}$ & $\begin{array}{l}\text { Factor III - Expression } \begin{array}{l}\text { of } \\
\text { oeelings and } \\
\text { evaluations" }\end{array} \\
\text { assertiveness } \\
\text { (complete test) }\end{array}$ \\
\hline low & 18,2 & 6,8 & 15,9 & 6,8 \\
\hline average & 79,5 & 72,7 & 75,0 & 79,5 \\
\hline high & 2,3 & 20,5 & 9,1 & 13,6 \\
\hline
\end{tabular}

The results of the analysis of the percentage distribution by individual factors represent the fact that most students demonstrating an average level of expression on all factors. A small proportion of students have a high level $(2.3 \%)$ of factor I. This means that there are students who are extreme in defending personal and consumer rights. They disagree, oppose, criticize and challenge allegations, object, resent. Impressive is the low percentage $(6.8 \%)$ of people with a low level of factor II - "Confidence and initiative" and the overall test. Students in 
this group still have difficulty expressing an opinion, insisting, initiating a conversation and maintaining it. They have difficulty making decisions, do not trust their own judgments and are not active. However, the majority of students in the sample have medium levels $(79.5 \%)$ and high levels (20.5\%) by factor II.

Table 2 presents the results of the survey of students on the indicator selfassessment to establish differences in the surveyed indicators between students and the normative sample (Table 2).

Table. 2. Results of the study of global self-esteem in students (\% of respondent)

\begin{tabular}{|l|l|l|l|}
\hline $\begin{array}{l}\text { Level } \\
\text { expression }\end{array}$ & $\begin{array}{l}\text { Factor I - "Self- } \\
\text { underestimation" }\end{array}$ & $\begin{array}{l}\text { Factor II - "Self- } \\
\text { esteem" }\end{array}$ & $\begin{array}{l}\text { Global self-assessment } \\
\text { (comprehensive test) }\end{array}$ \\
\hline low & 13,6 & 9,1 & 6,8 \\
\hline average & 63,6 & 79,5 & 72,5 \\
\hline high & 27,8 & 11,4 & 20,5 \\
\hline
\end{tabular}

The low levels in factor 1 and the overall test are less than those in the normal data distribution. These students have difficulty considering themselves worthy of respect, do not treat themselves well, and are generally dissatisfied with themselves. More than half of the students showed an average level on both factors and the overall test, i.e. these data do not differ from the results in the normative sample. $27.8 \%$ of them have a high level of factor 1 and the overall global self-assessment test. These students tend to perceive themselves as losers, feel useless, are not proud of themselves and would like to be respected more.

The main percentage distributions in the main dimensions of the Timothy Leary test within interpersonal relationships are as follows: friendliness $(81.8 \%)$ - hostility $(18.1 \%)$, as well as dominance $(56.8 \%)$ and obedience $(43.1 \%)$. Impressive is the prevailing orientation friendliness, which is striving to close a variation of trust and care.
Domination is a way for the "strong individual" to express his strength and at the same time to show concern and protection.

Table 3 presents the results of Timothy Leary's test for interpersonal relationships in the four social orientations- trust, care, aggression and anxiety (Table 3).

Impressive is the low level of orientation towards trust $(9.1 \%)$, as well as the high level of orientation towards anxiety $(61.4 \%)$. At the heart of the trust orientation are emotional structures that initially appear as roles in the system of mother-child relationships. Anxiety is another side of the trust system related to the protection system. The high level of anxiety orientation among students studying to become a nurse and midwife could be related to the lack of experience in the field of medical care, to being in an environment with both high requirements for training and clinical training, which unlock defence systems.

Table 3. Results of the study of students (\% of subjects) on a test of Timothy Leary

\begin{tabular}{|l|l|l|l|l|}
\hline $\begin{array}{l}\text { Level } \\
\text { expression }\end{array}$ & Trust & Concern & Aggression & Anxiety \\
\hline low & 9,1 & 11,3 & 11,4 & 2,3 \\
\hline average & 65,0 & 63,7 & 68,2 & 36,4 \\
\hline high & 25,0 & 25,0 & 20,5 & 61,4 \\
\hline
\end{tabular}

One-factor step-by-step regression analysis is used to check the degree of influence of the sequence of the training course on the assertiveness. The order of the course is taken as a predictor in the analysis, and the total score on the assertiveness test is taken as a result. No significant differences were found in any of the assertiveness factors. The results show that assertiveness is not affected by the order of the students' course. The specificity of the sample, consisting only 
of the first and second year of study, determines this fact. The short period of training does not provide enough opportunity to achieve significant personal development in the direction of assertiveness.

To check the degree of influence of the sequence of the training course on the selfassessment, the results show that there is no statistically significant influence of the training experience on the self-assessment in relation to the overall score. No significant differences were found in any of the factors of self-esteem. There is a tendency to increase the orientation towards aggression in second-year students. This side of the trust system depends on the degree of threat (threatening situation) with which students activate their defences system.

To check the degree of influence of the type of specialty on assertiveness and selfassessment was applied for two independent samples T-test.

Table 4 presents the data obtained during statistical processing by applying a T-test to two independent samples. This would establish differences between students in the two majors in terms of assertiveness and self-esteem (Table 4).

Table. 4. T-test- assertiveness and self-esteem between students- nurses and studentsmidwives.

\begin{tabular}{|c|c|c|c|c|c|c|}
\hline Indicator & Specialty & $M$ & $S D$ & $t$ & $d f$ & $p$ \\
\hline \multirow{2}{*}{ assertiveness } & nurse & 55,56 & 5,910 & \multirow{2}{*}{0,553} & \multirow{2}{*}{42} & \multirow{2}{*}{0,597} \\
\hline & midwife & 54,47 & 7,626 & & & \\
\hline \multirow[b]{2}{*}{ self-esteem } & nurse & 30,72 & 3,577 & \multirow[b]{2}{*}{$-1,001$} & \multirow[b]{2}{*}{42} & \multirow[b]{2}{*}{0,332} \\
\hline & midwife & 31,84 & 3,819 & & & \\
\hline
\end{tabular}

There are no statistically significant differences between nursing students and midwifery students, as for assertiveness $(\mathrm{t}$ $|44|=0.553 ; \mathrm{p}=0.597 ; \mathrm{M}_{\text {nurse }}=55.56 ;$ $\mathrm{SD}_{\text {nurse }}=5.910 ; \mathrm{M}_{\text {mid. }}=54,47 ; \mathrm{SD}_{\text {mid. }}=$ $7,626)$ and in terms of global self-esteem $\left(\mathrm{t}_{|44|}=-1,001 ; \mathrm{p}=0,332 ; \mathrm{M}_{\text {nurse }}=30,72\right.$; $\mathrm{SD}_{\text {nurse }}=3,577 ; \quad \mathrm{M}_{\text {mid. }}=31,84 ; \quad \mathrm{SD}_{\text {mid. }}=$ $3,819)$. However, the average values for midwives are higher than the average values for nurses.

The midwives show better self-esteem, which could be explained by longer training in the recent past compared to nurses, as well as the statement that "... a midwife can work as a nurse, but a nurse can't work as a midwife". Another important point of the midwife's work is related to the fact that they work mainly with healthy and not sick people (for whom duration of care and empathy in suffering is required), as well as the visible result, which is most often positive (birth of a child). Another important point in the midwife's work is related to the fact that they work mainly with healthy people, not sick people (who require duration of care and empathy for suffering), as well as with the visible result, which is most often positive (birth of a child)

Table 5 presents the results of a statistical T-test procedure for two independent samples to establish differences between students on the orientation scales of the Timothy Leary test (Table 5).

Statistically significant differences between the group of student nurses and the group of student midwives are indicated in terms of concern $\left(\mathrm{M}_{\text {mid. }}=7.81\right.$; $\mathrm{SD}_{\text {mid. }}=2.683 ; \quad \mathrm{M}_{\text {nurse }}=6.42 ; \mathrm{SD}_{\text {nurse }}=$ $\left.1.441 ; \mathrm{t}_{|44|}=2.219 ; \mathrm{p}=0.032\right)$. Account differences in the total score, the values of the average in student midwives are greater than the average values in students' nurses.

When analyzing data between the two groups in terms of trust $\left(\mathrm{M}_{\text {mid. }}=8.36\right.$; $\mathrm{SD}_{\text {mid }}=2.639 ; \quad \mathrm{M}_{\text {nurse. }}=5.84 ; \quad \mathrm{SD}_{\text {nurse }}=$ 1.772 ), the same trends are reported as the reported differences are statistically significant $\left(\mathrm{t}_{|44|}=3,800 ; \mathrm{p}=0,000\right)$. Differences in the total score were reported as the score values in the midwifery group were higher than the values in the nursing group. 
BACHEVA M

Table 5. T-test for two independent samples to determine the differences between nurses and midwives students on the orientation scales of the T. Leary test.

\begin{tabular}{|c|c|c|c|c|c|c|}
\hline Indicator & Specialty & $M$ & $S D$ & $t$ & $d t$ & $p$ \\
\hline \multirow[b]{2}{*}{ concern } & nurse & 6,42 & 1,441 & \multirow{2}{*}{2,219} & \multirow{2}{*}{42} & \multirow{2}{*}{0,032} \\
\hline & midwife & 7,81 & 2,683 & & & \\
\hline \multirow{2}{*}{ aggression } & nurse & 6,26 & 2,005 & \multirow{2}{*}{1,577} & \multirow{2}{*}{42} & \multirow{2}{*}{0,122} \\
\hline & midwife & 7,31 & 2,433 & & & \\
\hline \multirow{2}{*}{ anxiety } & nurse & 8,42 & 2,070 & \multirow{2}{*}{2,135} & \multirow{2}{*}{42} & \multirow{2}{*}{0,039} \\
\hline & midwife & 9,76 & 2,064 & & & \\
\hline \multirow{2}{*}{ trust } & nurse & 5,84 & 1,772 & \multirow{2}{*}{3,800} & \multirow{2}{*}{42} & \multirow{2}{*}{0,000} \\
\hline & midwife & 8,36 & 2,639 & & & \\
\hline
\end{tabular}

After applying a hypothesis testing procedure, statistically significant differences were found in the two groups of subjects on the indicator anxiety $\left(\mathrm{M}_{\text {mid. }}=9.76 ; \mathrm{SD}_{\text {mid }}=2.064 ; \mathrm{M}_{\text {nurse. }}=8.42\right.$; $\left.\mathrm{SD}_{\text {nurse }}=2.070 ;\left.\mathrm{t}\right|_{44 \mid}=2.135 ; \mathrm{p}=0.039\right)$. There is a clear increase in the values of the general score of the midwives compared to the values of the nurses.

There are no differences between the two groups in terms of the indicator of aggression $\left(\mathrm{M}_{\text {mid. }}=7.31 ; \mathrm{SD}_{\text {mid. }}=2.433\right.$;
$\left.\mathrm{M}_{\text {nurse }}=6.26 ; \mathrm{SD}_{\text {nurse }}=2.005\right)$, however, there is a tendency to more high mean values in midwifery students compared to those in nursing students.

Table 6 presents the results by individual sectors (octants) in the discogram of Timothy Leary to establish quantitative relationships in significant characteristics between students in both majors. This set of traits describes the type of interpersonal relationship (Tabl 6).

Table. 6. Distribution of results by octants O1-O8

\begin{tabular}{|l|l|l|l|l|l|l|l|l|}
\hline $\begin{array}{l}\text { Level of } \\
\text { expression }\end{array}$ & Octant 1 & Octant 2 & Octant 3 & Octant 4 & Octant 5 & Octant 6 & Octant 7 & Octant 8 \\
\hline 1 (low) & 63,6 & 100 & 88,6 & 70,5 & 77,3 & 79,1 & 38,6 & 40,9 \\
\hline 2 (moderate) & 25,0 & 0 & 44,4 & 27,3 & 18,2 & 16,3 & 61,4 & 59,1 \\
\hline 3 (high) & 11,4 & & & 2,3 & 4,5 & 4,7 & & \\
\hline
\end{tabular}

Following the analysis of the data on the individual octants from the Leary test, it was found that there is a clear tendency for predominantly low (authoritarian, selfish, aggressive, suspicious, submissive, dependent type) and medium levels of expression (friendly, altruistic type) on the individual octants. The content of each octant represents the behavior of people in low and moderate levels and determine the personal profile of students in both disciplines by including characteristics of different types of interpersonal relationships. The style of interpersonal relationships includes the following characteristics: from self-confident, persistent and persistent, good counsellor, mentor and organizer (authoritarian type) to a tendency to rivalry and complacency (selfish type); rectilinear, stubborn, persistent, energetic (aggressive type); realistic in reflection and actions (suspicious type). Modest, compliant, emotionally restrained able to obey. He has no opinion of his own, obedient and honest in his duties (subordinate type). Conformal, trusting, seeking constant trust from others, and their recognition (dependent type). Prone to cooperation and cooperation in solving problems (friendly type).

The exception is a result Octant 8- there dominate the higher levels of markedness altruistic type of interpersonal relationships as a set of features includes excessive responsibility, a sacrifice of their interests, striving for help, and compassion to all.

The conclusions that can make of this study generally can be submitted:

1. The level of assertiveness and selfesteem nurses and midwives for the most part is not different from the normative sample.

2. Assertiveness and self-esteem are not affected by the sequence of the training course.

3. Midwifery students show higher results in terms of assertive behavior and selfesteem than nursing students, and the 
reported differences are statistically significant.

4. The majority of students show orientation is mainly towards friendliness and dominance.

5. Most students show an orientation towards trust, concern and anxiety.

6. Many students demonstrate a high level of anxiety orientation.

7. There is a clear tendency for predominant low and medium levels of significance in the individual octants.

\section{DISCUSSION}

The study revealed results that do not differ statistically significant from the normative sample, i.e. students studying to be nurses and midwives randomized to participate in this study demonstrated a level of assertiveness and self-esteem within the norm. However, there is a slight tendency for higher results in the group of midwives in terms of assertiveness and self-esteem.

The results of the individual octants from the test for interpersonal relationships build the personal profile of the subjects. Most students in the sample demonstrate adaptive behavior and their profile have moderately pronounced traits of the authoritarian, friendly, aggressive and altruistic type of interpersonal relationships. At the same time, there are no characteristics included in the selfish, suspicious, dependent type of interpersonal relationships. This set of traits, building the profile of the health care professional, can be considered as target units, and stimulate to an appropriate socially significant orientation in behavior, meeting the needs of the two regulated professions.

\section{CONCLUSION}

Summarizing the literature, we believe that students studying in the two regulated professions should be encouraged to act autonomously and as advocates for patients, by generating assertive skills that are embedded in educational programs. Therefore, students need to practice their skills through demonstration, role-plays and experience in practical laboratories, as well as assertive training, so that they can receive support, direction, and feedback from academic nursing. This allows for the practice of these skills in a safe environment that can be observed by teachers, assessed and given feedback (17).

\section{REFERENCES}

1. Fedosenko, A. Uverenost $\mathrm{v}$ sebe kak integrativnih pokazatel kachestva jizni.Sbornik nauchnih trudov AziatskoTichookeansom regione, UjnoSakhalinsk, s.135-146,2006

2. Lin, Y., I. et al. Evaluation of an assertiveness training program on nursing and medical students' assertiveness, selfesteem and interpersonal communication satisfaction. Nurse Education Today, 24 (8), 656-65, 2004

3. Bishop, Sue. Develop Your Assertiveness. Kogan Page, London, 2006

4. Benner, P. et al. Educating Nurses: A Call for Radical Transformation, 1st Edition, 2010

5. Peneva, I. Bulgarian adaptation of the personality scale for the study of assertiveness. Yearbook of Psychology, Blagoevgrad, pp.315-333, 2012

6. Timmins, F., McCabe, C. Nurses 'and midwives' assertive behavior in the workplace. J Adv Nurs .; 51 (1), 38-45, 2005

7. Chambers DW. Assertiveness. J Am Coll Dent. 2009;76(2):51-58.

8. Clark S. Holistic Assertiveness Skills for Nurses: Empower Yourself (and Others). Springer Publishing Company,2003

9. Amicone, K., M., Rachel. Assertiveness in Nursing Students. Honors Research Projects, 2015.

10.Bylund CL, Peterson EB, Cameron KA. A practitioner's guide to interpersonal communication theory: an overview and exploration of selected theories. Patient Educ Couns. 2012;87(3):261-267.

11.Bachewa, M. Assessment of stressinduced reactivity in a student nurse and midwife. Nursing, no.2, p. 3-12, 2018, ISSN 1310- 7496

12.Bachewa, M., I. Peneva. Assertiveness in the field of medical heating. Collection "Psychology in Medicine", Stara Zagora, Thracian University, p. 37-43,2014

13.Callaway, B. Hildegard Peplau: Psychiatric Nurse of the Century Springer Publisher Company, Ins., NY, 2002, ISBN 0-8261-3882-9

14.Donkina V., R. Doinovska. Emotional 
intelligence and psychological literacy in medical heating. Nursing work, no.3, p. 24-28,2012, ISSN 1310- 7496

15.Stoianova, St., Peneva, I. Methodological guide for conducting empirical psychological research. Blagoevgrad, UI, UZU "N.Rilski",2014.

16.Karabeliov, S., I.Peneva. Stages in the conduct of empirical research. Proceedings of the XXVI International Conference for Young Students, pp.175180, 2016

17.Zavertnik, J., Huff, T., Munro, C. Innovative approach to teaching communication skills to nursing students. Journal Nursing Education, 49 (2), 6571,2010 
BACHEVA M 